\title{
Da Saúde de Ontem à Saúde de Hoje: A Formação de Professores desde a História Natural às Ciências Biológicas no Brasil
}

\author{
The Health from the Ancient Times to the Current Days: The Teacher \\ Training through the Natural History of Biological Sciences in Brazil
}

\section{Luan Gustavo $^{\text {; }}$ Tatiana Galieta ${ }^{a}$}

a Faculdade de Formação de Professores, Universidade do Estado do Rio de Janeiro, São Gonçalo, Brasil luan.gustavo.ufrj@gmail.com, tatigalieta@gmail.com

Palavras-chave:

Educação em saúde.

História natural.

Licenciatura em ciências biológicas. Formação de professores.
Resumo: O presente artigo apresenta uma investigação histórica que lançou mão de documentos com diretrizes reguladoras das áreas da Saúde e Educação, documentos produzidos em conferências e estudos do campo de Educação em Saúde (ES) com a finalidade de argumentar a pertinência da questão da saúde na Formação de Professores (FP). Além de analisar se as diretrizes orientadoras para a FP se relacionam com as regulações da educação básica no que tange à saúde, visto que a saúde, desde o final do século XIX, é uma demanda real da educação básica a ser enfrentada pelos professores no cotidiano da docência. Centramos nossas reflexões na FP desde a História Natural às Ciências Biológicas, devido a sua importância para a questão da ES. O estudo indica que não havia diálogos entre as diretrizes curriculares da educação básica e a FP, apenas nos documentos mais atuais, após o ano 2000, encontrou-se alguma relação.

Abstract: This article presents a historical research that has used issues of documents with regulatory guidelines in the fields of Health and Education, documents produced in Conferences and studies about Health Education with the purpose of arguing the relevance of the issue of Health in Education Training Programme for Teachers in addition to analysing if the regulatory guidelines for the Teachers Training are related to Basic Education Regulation regarded to Health. As Health since the end of the XIXth century is a real demand of the Basic Education to be dealt by Teachers daily teaching, focusing our joint thinking in Teacher Training from Natural History to Biological Sciences due to its importance for Health Education. The study indicates that there had been no dialogues between the Curricular Guidelines of Basic Education and the Training Teachers, only on current documents after the year 2000 it has been found some relationship between. 


\section{Introdução}

As concepções sobre saúde sofreram modificações paulatinamente ao longo da história do próprio Brasil. O conceito de saúde esteve cercado por concepções religiosas; reduzidas aos aspectos biológicos e/ou fisiológicos ou contextualizada com aspectos sociais, culturais e econômicos. Com isso, ao longo da história, diferentes sujeitos estiveram envolvidos pelo dever de disseminar, informar e educar em saúde. No presente trabalho, centramo-nos no período em que o professor passa a ser considerado sujeito chave para as ações promotoras da saúde que se desejavam disseminar. Assim, estruturamos uma investigação histórica que se propôs a alinhavar uma interface entre a Saúde e a Educação, no que tange o objetivo de entender as aproximações ou distâncias entre a regulação da Educação em Saúde (ES) na educação básica e na Formação de Professores (FP) no ensino superior.

A questão da saúde é uma demanda real da educação básica desde o final do século XIX e início do século XX, neste contexto, os professores têm figurado como sujeitos chave no dever de educar em saúde. Desta forma, objetivamos entender, historicamente, se ou como a FP considera a questão da saúde. Para tanto, analisamos documentos reguladores das áreas da Saúde e Educação, documentos produzidos em conferências e estudos do campo de ES.

Propomos um caminho de pesquisa em que traçamos um paralelo entre o levantamento de dados e discussões sobre a saúde na educação básica e, por conseguinte, na FP. Adotamos essa estratégia como forma de entender o quanto/ ou se as regulações da saúde para a educação básica se relacionavam com aquelas para a formação dos professores, e vice e versa, dado que seriam os profissionais que futuramente lecionariam nas escolas.

Entretanto, embora iniciemos abordando a figura do professor sem fazer a distinção de área disciplinar, adensamos nossas investigações na formação de professores desde a História Natural às Ciências Biológicas, visto que o entendemos como o principal docente responsabilizado historicamente pela saúde na educação básica (FOCESI, 1990; MOHR, 2002; GOUVÊA, 2007; BAGNATO, 1990; LEMÔNACO, 2004, apud VENTURI; MOHR, 2011). Os autores referenciados argumentam direta e indiretamente que o destaque dos professores da referida área como os principais atores, ao que se refere à abordagem da saúde no ambiente escolar, se deu principalmente pelo ideário reduzido que circundava o conceito de saúde, reduzindo-o aos aspectos biológicos e/ou fisiológicos. Todavia, os professores de Ciências Biológicas permanecem figurando como sujeitos chave na ES a ser promovida na educação básica.

Os dados levantados, apresentados e discutidos neste estudo compõem o escopo da revisão bibliográfica da pesquisa de mestrado do primeiro autor. A dissertação foi dedicada a investigar se os cursos de formação de professores de Ciências Biológicas, as Licenciaturas 
em Ciências Biológicas (LCB), situadas na cidade do Rio de Janeiro e sua região metropolitana, nos anos 2015 e 2016, propunham a ES na formação de seus egressos. Assim, a revisão empreendida como pesquisa histórica foi fundamental para a criação das justificativas e questões de pesquisa, como também a construção de argumentos sobre a pertinência de um estudo que se dedicasse a tal temática na atualidade.

Neste artigo apresentamos os diferentes caminhos e processos de inserção da saúde na educação básica, contextualizando-os com a conjuntura histórica, política e econômica brasileira desde o final do século XIX até a atualidade. Em seguida, recuperamos, historicamente, a inserção da saúde nos cursos de FP em nível superior, visto que estes profissionais, após formados, lecionam no ensino secundário escolar. Por fim, tecemos algumas considerações finais traçando paralelos entre o passado e o presente, no qual consideramos a trajetória tratada no artigo e a perspectiva atual da ES sob as regulações mais recentes estabelecidas em um cenário de maior aproximação entre as diretrizes para educação básica e a FP.

\section{A interface entre saúde e educação: o ambiente escolar}

Demarcamos o século XIX como ponto de partida, porque nele se configurou o contexto que impulsionou a busca de condições "aceitáveis" de saúde. A chegada da Família Real em terras brasileiras acarretou modificações significativas para a até então colônia, dentre as modificações, destaca-se o impacto na economia com a intensificação da produção cafeeira, que passou a gerar excedentes. O crescimento exponencial da produção agrícola, com o café sendo produzido em larga escala, desencadeou ações no setor de saúde pública que passou a intervir nas principais vias econômicas fundamentais para o escoamento da produção como: grandes cidades, ferrovias e portos, no combate às doenças infectocontagiosas. As medidas de intervenção eram realizadas com o objetivo de que fossem obtidas as mínimas condições sanitárias condizentes com o mínimo, em saúde pública, indispensável a um país que almejasse entrar no ciclo de países agroexportadores (GOUVÊA, 2007).

As intervenções do setor de Saúde Pública foram traduzidas em ações diretas como reorganização do espaço urbano com a limpeza dos portos, a remoção dos aglomerados de moradias populares (cortiços) e também em ações indiretas como a tomada da escola e de seus programas de ensino como aparelho disseminador de um novo ideal comportamental que fosse condizente com a saúde. A escola passa a ser entendida como um espaço propício para disseminação de um novo ideário sobre saúde, porque seus frequentadores, crianças e adolescentes, viviam neste ambiente durante anos consecutivos até que se formassem. 
Portanto, nada mais promissor do que inculcar novos hábitos salutares na formação das futuras gerações da elite brasileira, visto que os frequentadores da escola eram os filhos da elite, burguesia e descendentes da aristocracia real. Logo, para que fosse possível a disseminação de um novo ideário sobre saúde no ambiente escolar, os cursos de formação dos futuros professores passaram a ter em seus programas, disciplinas direcionadas a abordagem de conteúdos sobre saúde. Porém, as abordagens eram realizadas sob uma perspectiva higienista centrada no indivíduo.

Já no início do século XX, porém ainda com toda influência dos movimentos de modificação da estrutura brasileira do século XIX, a escola permanece assumindo o papel de disseminadora de novos costumes saudáveis, de desenvolver uma educação Higienista com ações diretas de inspeção da saúde na rotina escolar (escovação de dentes, pesos e medidas, catação de piolhos), quanto indiretas através dos programas de ensino como nos sinalizam Collares e Moysés (1985). Tão consequentemente, os cursos de formação de professores permanecem valorizando a higiene em seus programas de ensino. A tomar como exemplo a Escola Normal/Instituto de Educação do Distrito Federal que no ano de 1904 ofertava no $4^{\circ}$ ano, com três horas semanais, a disciplina Higiene em seu programa (SANTOS, 2014).

Para as camadas populares, que não tinham acesso à escola, a inculcação de novos hábitos desejáveis e condizentes com uma vida saudável era realizada através de fiscalizações e controle sanitário pelo poder da polícia. A polícia sanitária era fundamentada por uma fiscalização policial que representava uma forma de ação sanitária justificada pelo conceito de doença e suas formas de transmissão, de acordo com os conhecimentos científicos da época. Contudo, ficou caracterizada por sua ação coercitiva que causou um movimento de oposição pela população alvo (GOUVÊA, 2007).

A Educação Sanitária surgiu no marco histórico da Conferência Internacional sobre Criança, nos Estados Unidos em 1919, quando o termo foi cunhado pela primeira vez. O Brasil, por sua vez, como um país signatário, adotou os modelos de Educação Sanitária sendo a década de 1920 considerada como marco histórico da institucionalização da Educação Sanitária. Mais precisamente, em 1925, uma reforma política substituiu a Polícia Sanitária pela Educação Sanitária.

No contexto educacional brasileiro, já no período da República Velha, dois movimentos educacionais impulsionados por intelectuais da oligarquia cafeeira se complementaram e se alternaram, foram eles: "o movimento de entusiasmo pela educação que solicitava a abertura de escolas e o movimento do otimismo pedagógico que solicitava a mudança dos métodos e conteúdos do ensino" (SILVA, 2007, p. 1). Neste cenário educacional, o segundo movimento prevaleceu ao longo das décadas de 1920 e 1930, 
tornando-se popularmente conhecido como o movimento da Escola Nova. Dentre as reivindicações deste movimento educacional, figuravam principalmente a defesa do ensino público, gratuito, obrigatório e laico, o que significou a abertura das portas da escola para a população em geral e não somente para a elite brasileira. Porém, uma abertura ideologicamente orientada que visava uma formação civilizatória determinada pela elite intelectual do país que passava a se organizar em uma lógica liberal (SILVA, 2007).

O que os renovadores da educação apontavam era a necessidade de republicanização da República, de democratizar e de modernizar a educação a fim de que esta educação moderna pudesse atender as exigências de um capital industrial urbano e de uma burguesia liberal em formação. Nas décadas de 1920 e 1930, tal modernização implicava qualificar técnicos e dirigentes, bem como civilizar as classes populares, tendo como horizonte o fortalecimento de uma consciência nacional delineada por uma elite de intelectuais vinculados ao Estado (SILVA, 2007, p. 3).

O movimento da Escola Nova coincide com o período em que a Educação Sanitária substituiu o modelo coercitivo da Polícia Sanitária até então direcionado às camadas populares. A exemplo do que sinaliza Silva (2007) sobre uma liberalização da educação brasileira orquestrada pela burguesia, a Educação Sanitária simboliza o rompimento com um modelo coercitivo de disseminação de conhecimentos sobre saúde, pois atinge às classes populares recém-chegadas à escola através dos currículos e programas de ensino. Por outro lado, ela ainda não rompe com o modelo de abordagem diretiva da saúde ao restringir a educação sobre saúde que tem como objetivo educar indivíduos, principalmente crianças, permeado pelas noções de higiene, medidas preventivas, imunizações e cuidados individuais (CARDOSO DE MELO, 1981).

Retomamos para exemplificação o caso dos programas de ensino da Escola Normal/Instituto de Educação do Distrito Federal tomados pelo estudo de Santos (2014), principalmente por consistir em uma instituição de destaque, que servia de modelo e influenciava os programas de ensino e currículos de outras instituições do país. Compreendemos através desta autora que embora com algumas alterações como: o momento em que era oferecida no curso e tempo de duração semanal, a presença da disciplina Higiene se manteve estável em praticamente todos os programas de ensino da referida instituição de formação de professores primários de 1904 até o ano de 1946. Interpretamos estas informações como dados que nos ajudam a compreender a importância atribuída à escola na tarefa de disseminação de um novo ideário sobre saúde (SANTOS, 2014). É importante ressaltar que temos total clareza de que inúmeros fatores contribuem para a fixação de uma disciplina no programa de ensino de uma instituição de educação, porém chamamos a atenção para este fato como um indício da importância atribuída à escola na disseminação de novos 
costumes, e principalmente, a importância de uma disciplina com esse caráter na formação de professores que futuramente atuarão na escola.

A década de 1950 é marcada pela intensificação de um dos caminhos pelo qual é promovida a entrada dos conteúdos de saúde na escola: via visitas de profissionais de saúde e educadores sanitários buscando técnicas de regulação e normatização. A Fundação de Serviço Especial de Saúde Pública (SESP) desenvolvia uma Educação Sanitária sustentada por novas tecnologias educacionais que se propunham a intervir socialmente modificando comportamentos e gerando mudanças culturais.

Já no ano de 1961 foi promulgada a primeira Lei de Diretrizes e Bases da Educação Nacional (LDB) (BRASIL, 1961), contudo, o documento não trouxe designação alguma sobre a abordagem da saúde nos programas de ensino e currículos escolares. A única ressalva referia-se que, dentre as disciplinas em que poderia ocorrer alguma abordagem da saúde, localizavam-se as Ciências Físicas e Biológicas e a Biologia (GOUVÊA, 2007).

Apenas uma década mais tarde com a promulgação da LDB de 1971 (BRASIL, 1971) que a abordagem da saúde foi fixada na educação básica brasileira. Três anos após a vigência da LDB/71, o Parecer 2.264/1974 regulamentou os Programas de Saúde a serem desenvolvidos nas escolas com o intuito de romper com a abordagem reducionista da saúde herdada do século anterior. Como principal estratégia de inovação, o parecer propunha que a saúde fosse abordada interdisciplinarmente, de modo a contar com a contribuição das diferentes áreas disciplinares que compõem o currículo da educação básica. Entretanto, na prática, os Programas de Saúde serviram apenas para a criação de mais uma disciplina escolar e para produção de materiais didáticos, pois os conteúdos do tema saúde trabalhados nas escolas ainda eram fortemente marcados pelas intenções sanitaristas e higienistas (MOHR, 2002).

Os Programas de Saúde consistiam basicamente em orientações de como seria desejável a realização da abordagem interdisciplinar da saúde no currículo da educação básica, porém tanto a LDB/71 quanto o Parecer 2.264/1974 não trouxeram apontamentos para operacionalização de tal abordagem. Como exemplo, trazemos a questão da formação de professores, pois embora a saúde tenha sido posta como um conteúdo fixado através de diretrizes e parecer, em nada foi modificada a formação dos professores que futuramente lecionariam nas escolas. Desta forma, o desenvolvimento dos Programas de Saúde ficou restrito às disciplinas Ciências e Biologia, logo, os professores destas disciplinas passaram a ser os principais responsáveis pela abordagem da saúde no ambiente escolar (MOHR, 2002; GOUVÊA, 2007; BAGNATO, 1990; LEMÔNACO, 2004, apud VENTURI; MOHR, 2011). 
Entendemos que isso ocorreu pelo fato da saúde ainda nas décadas de 1970 e 1980 ser fortemente marcada pelas intenções higienistas, sanitaristas do século anterior (MOHR, 2002). Não que a abordagem da saúde pelas disciplinas Ciências e Biologia se satisfaça pela consideração destes poucos aspectos, mas naquele contexto, os professores de Ciências e Biologia eram os mais aptos a realizarem alguma abordagem devido à afinidade entre os conteúdos estabelecidos pelos Programas de Saúde e os das disciplinas Ciências e Biologia.

No contexto mundial, principalmente a partir da I Conferência Internacional Sobre Cuidados Primários de Saúde, realizada no ano de 1978 em Alma-Ata pela Organização Mundial da Saúde em colaboração com o Fundo das Nações Unidas para a Infância (Unicef), fatores mais amplos que interferem diretamente na saúde de um indivíduo ou de um grupo de indivíduos passaram a ser considerados nas discussões sobre saúde. Estes fatores foram chamados de condicionantes de saúde (biológicos, psicossociais, culturais, ambientais ou socioeconômicos), sendo considerados fundamentais para a manutenção ou/e recuperação da saúde (FREITAS; MARTINS, 2008).

Em 1986, aconteceu em Ottawa-Canadá a I Conferência Internacional sobre Promoção da Saúde, na qual foi atribuída e reconhecida a importância dos processos educativos para que se pudesse promover a saúde, como destacamos:

\footnotetext{
A promoção da saúde é o resultado de um conjunto de fatores sociais, econômicos, políticos e culturais, coletivos e individuais, que se combinam de forma particular em cada sociedade e em conjunturas específicas, resultando em sociedades mais ou menos saudáveis (BUSS, 2010, p. 2).
}

Outro marco desta conferência consistiu na redefinição do conceito de saúde, que passou a ser ampliado por uma perspectiva que abarcava aspectos de diferentes ordens até então não considerados no conceito, dando reconhecimento à influência do social sobre a saúde. O Brasil como país signatário, divulgou através de relatório do Ministério da Saúde os novos aspectos que deveriam ser considerados no conceito de saúde, tais como: "habitação, alimentação, educação, renda, meio ambiente, trabalho, transporte, emprego, lazer, liberdade, acesso e posse da terra e acesso a serviços de saúde" (BRASIL, 1986, p. 4).

Ainda ao que se refere ao campo da saúde, a Constituição Federal Brasileira de 1988 instituiu um novo modelo de funcionamento do serviço de saúde, o Sistema Único de Saúde (SUS), que consistia em um novo modelo de funcionamento do serviço de saúde, com um ideário de seguridade social envolvendo não somente questões relacionadas ao campo da Saúde, mas também com as políticas de previdência e assistência social. A partir de então, o Estado assumiu a saúde como um direito de todos e um dever do próprio Estado, que embasado por políticas sociais e econômicas se comprometia com a redução do risco de doenças e de outros agravos e políticas de saúde capazes de garantir o acesso universal e igualitário às ações e serviços para promoção, proteção e recuperação da saúde da população 
(BRASIL, 1988, art. 196). Para tanto, o SUS é norteado por diferentes princípios que fundamentam a lógica do seu funcionamento como: universalização do acesso às ações e serviços de saúde; integralidade da atenção; descentralização, com direção única do sistema e participação popular (BAPTISTA, 2007).

É importante frisarmos que esse modelo de sistema está alinhado com a forma de pensar saúde disseminada pelo mundo, muito orientado por uma lógica liberal de padronização, inclusive de condições de saúde e serviço. Todavia, é de suma importância mencionar que para além da ação de uma força liberalizante que se entremeia na estrutura do novo sistema de saúde, forças sociais participaram ativamente para ressignificação do sistema desde sua origem. Diferentes atores sociais estiveram historicamente atrelados à militância organizada pela bandeira da saúde e, como materialização da luta, damos destaque ao princípio da participação popular do SUS, enunciado na Constituição de 1988 e regulamentado na lei do SUS de 1990 (lei 8.142/1990), pois defende que em cada esfera de governo deve haver uma representação da população para que haja mais transparência nos processos decisórios (BAPTISTA, 2007).

Compreendemos que o princípio da participação popular constitui um espaço para atuação do povo no exercício de sua cidadania e também um espaço no qual o cidadão não se configura simplesmente como um usuário do SUS, mas sim como um indivíduo que sugestiona e, em certa parte, gere o serviço que o atende em saúde. Isto deveria acontecer a partir do instante em que este se compromete com a participação nos espaços de decisão reservados à representação popular, como conselhos e conferências de saúde. Não obstante, compreendemos também que para que o indivíduo seja atuante, para que exerça sua cidadania, ele necessita de uma formação. Assim, dispomo-nos a refletir sobre qual o espaço, atualmente, está incumbido pela formação do indivíduo para atuação nos lugares definidos pelo princípio da participação popular do SUS. Entendemos que muitos espaços e modalidades de educação não formais ou informais podem proporcionar tal formação para atuação do indivíduo, mas nos dedicamos a refletir, mesmo que indiretamente, sobre a escola atual e o compromisso com a abordagem de conteúdos atitudinais e criação de valores para a tomadas de decisões ligadas à saúde.

Retornamos ao campo da educação com a intenção de evidenciar historicamente a construção da interface entre a Saúde e a Educação. A LDB/71 foi substituída pela Lei de Diretrizes e Bases da Educação Nacional de 1996 (BRASIL, 1996), que por sua vez não fixou diretrizes sobre o tema saúde na educação básica. Apenas com a criação dos Parâmetros Curriculares Nacionais (PCN) do Ensino Fundamental (BRASIL, 1998), o tema saúde tornouse assegurado no ambiente escolar. Os PCN sugerem a partir da proposição dos Temas 
Transversais - Ética, Saúde, Meio Ambiente, Pluralidade Cultural e Orientação Sexual - uma prática educacional voltada para a compreensão da realidade social e dos direitos e responsabilidades em relação à vida pessoal, coletiva e ambiental através da abordagem de questões importantes, urgentes e presentes de várias formas, na vida cotidiana (BRASIL, 1998). Cabe ressaltar que esta abordagem abrangente que leva em conta inúmeros determinantes só é possível pelo caráter transversal de cada um dos temas, consistindo em uma abordagem a ser realizada pelas diferentes áreas disciplinares que compõem o currículo da educação básica.

Entretanto, os PCN tornaram-se pouco efetivos na implementação dos temas transversais, porque assim como nos Programas de Saúde da década de 1970, a abordagem da saúde na educação básica tornou-se oficialmente garantida, porém os parâmetros curriculares não trouxeram apontamentos para sua operacionalização no cotidiano escolar. A parte disto, a formação de professores seguiria desconectada dos novos desafios postos na realidade da escola. Acreditamos ter sido um avanço a forma pela qual a abordagem da saúde foi arquitetada para o cotidiano escolar tanto pelos Programas de Saúde quanto pelos PCN, porém qualquer tipo de determinação ou sugestão curricular torna-se limitada se ela não traz apontamentos operacionais e, principalmente, encaminhamentos para a formação dos professores que atuam e/ou atuarão nas escolas.

O Programa Saúde na Escola (PSE) é um programa comprometido com a ES que surge como proposta de uma política intersetorial entre os Ministérios da Saúde e da Educação, tendo sido instituído pelo decreto presidencial n ${ }^{\circ}$ 6.286, de 5 de dezembro de 2007 . Orientado pelas diretrizes do SUS, o programa assume a perspectiva da atenção integral (prevenção, promoção e atenção) à saúde de crianças, adolescentes e jovens matriculados em diferentes modalidades de educação do ensino básico público, desde que tal atenção ocorra no âmbito das escolas e/ou das unidades básicas de saúde e seja proporcionada pelas equipes de saúde da família (BRASIL, 2007).

Por uma ótica mais generalizada, pois tratamos de uma política pública educacional brasileira, consideramos que o PSE parece finalmente reconhecer um espaço de ação deixado em aberto pela Constituição Federal de 1988 com a criação do SUS. A proposta de criação do programa a partir da articulação entre os Ministérios da Saúde e Educação soa como algo promissor, pois justapõe interesses contíguos entre os dois campos. Desta forma, fortalece, concomitantemente, a implementação efetiva do SUS a partir de apoios educacionais do programa e o desenvolvimento de uma ES no âmbito escolar, sustentada pelo trabalho conjunto entre equipes de profissionais da saúde, profissionais da educação e toda a 
comunidade escolar, incluindo processos de aproximação, formação, planejamento, execução e avaliações das ações de ES.

A articulação interministerial é forjada a partir do próprio texto que embasa o PSE, pois o texto partilha das mesmas fundamentações teóricas do próprio SUS. É possível notar correlação entre as diretrizes do PSE e os princípios orientadores do SUS como se observa: Descentralização e respeito à autonomia federativa do PSE que se equipara com Descentralização e comando único do SUS; Territorialidade com Regionalização e hierarquização; Integralidade com Integralidade e Controle Social com Participação Popular, respectivamente (EBERHARDT; REIS, 2011). Sendo assim, o funcionamento pleno do PSE, pode constituir a escola como um espaço de empoderamento do indivíduo para tomada de decisão e atuação cidadã nos espaços reservados pelo SUS à participação popular.

Contudo, o PSE apresenta algumas limitações consideráveis. A LDB de 1996 legitima a existência das instituições privadas de ensino, principalmente, com vistas ao atendimento a toda população, pois a rede pública não atenderia tal demanda; no entanto, o PSE é direcionado apenas aos estudantes matriculados na educação básica da rede pública de ensino. Outro fator que restringe ainda mais a abrangência de alcance do PSE é a implementação do programa estar condicionada aos municípios em que atuem equipes de saúde da família. Ambos os fatores impedem que o PSE esteja plenamente atrelado aos princípios orientadores de SUS, pois tais restrições ferem, por exemplo, o princípio da universalidade.

Acreditamos que o PSE seja um programa instituído a partir do acúmulo do diálogo histórico entre os campos da Educação e da Saúde, sendo que a institucionalização desse programa não demarca um rompimento com as orientações ao trabalho com a ES na escola dadas pelo PCN. Visualizamos no programa intenções mais amadurecidas sobre uma ES que se proponha desenvolver no espaço escolar e identificamos propostas que consolidam a interface entre a Saúde e a Educação na concepção do programa. Apenas uma análise aprofundada do cotidiano de aplicação do PSE nos permitiria fazer avaliações mais precisas, aqui nos detemos ao texto descritivo do programa, no qual identificamos alguns avanços, na interface entre Saúde e Educação ao fundamentar as diretrizes um programa que se dedica à escola nos princípios reguladores do SUS; mas também alguns entraves, pela limitação do programa aos municípios da federação que sejam contemplados por uma equipe da saúde da família. Esperamos que estes apontamentos e reflexões possam ser somados a outros estudos e, desta forma, contribuam para avanços e melhorias da ES. 


\section{A saúde na formação de professores no Brasil: as licenciaturas em História Natural e Ciências Biológicas}

As tentativas de criação da educação em nível superior no Brasil se tornaram evidentes nas três últimas décadas da Primeira República compreendida no período de 1889 a 1930. Despontam no contexto nacional esforços de estruturação de instituições universitárias como no Amazonas em 1909, em São Paulo no ano de 1911 e no Paraná no ano de 1912; porém estes esforços não se consolidaram (CUNHA, 1980). Anos mais tarde, mais precisamente em 7 de setembro de 1920, é criada a Universidade do Brasil, e sua criação é um novo convite à reflexão sobre a configuração do ensino superior no país (FAVERO, 2007).

Como tratado em seção anterior, a década de 1920 foi marcada por fortes movimentos que reivindicavam modificações na educação nacional e que exerceram influências nas décadas seguintes. Outros acontecimentos conjunturais como o desenvolvimento econômico a partir do processo de industrialização de grandes cidades brasileiras, principalmente as cidades do Rio de Janeiro e São Paulo marcaram esta década. Os apontamentos dados pelos movimentos ligados à educação e o contexto de desenvolvimento econômico-industrial permearam direta e indiretamente as discussões sobre o papel da universidade, que ainda incipiente, era estruturada no Brasil. Essas influências materializavam-se dicotomicamente entre os que defendiam uma formação universitária para a pesquisa científica e formação intelectual e àqueles que defendiam uma formação universitária voltada à formação profissional (FAVERO, 2007).

Sendo assim, o ensino superior foi organizado inicialmente sob a forma de cadeiras, sucedidas pela organização em cursos, sequencialmente estruturadas em escolas, até a conformação das faculdades como: medicina, direito, engenharia, agronomia; todos cursos de especialidade técnica, direcionados ao exercício de uma profissão e por isso denominados por alguns autores de faculdades profissionais (CACETEII, 2010). Todavia, a Reforma Francisco Campos se deu em contraposição à expansão das faculdades profissionais criadas para a formação de mão de obra especializada para o mercado em crescimento exponencial, direcionando-se ao ensino superior baseada pelo Decreto $\mathrm{n}^{\circ} 19.851$, de 11 de abril de 1931, que ficou conhecido como o Estatuto das universidades brasileiras. Tal reforma preconizou a criação das Faculdades de Filosofia, Ciências e Letras como centros de alto saber, comprometidos com a promoção de estudos não profissionais. O principal intento da criação destas faculdades foi a formação de uma elite intelectual no Brasil por meio de uma formação geral centrada na filosofia, na organicidade às formações de ensino superior e introdução aos estudos pedagógicos (CACETEII, 2010). O Decreto ${ }^{\circ} 19.851$ apresentava ênfase na proposta de articulação do ensino superior para que se alcançasse um caráter universitário; no entanto, 
o documento foi pouco diretivo no que se refere à orientação de conteúdos a serem desenvolvidos na formação em ensino superior como um todo e, principalmente, na formação de professores.

A proposta de criação de cursos não profissionais não se constituiu plenamente, pois embora o objetivo não fosse formar para o exercício de profissões como medicina, direito, engenharia e agronomia, os cursos criados pelas Faculdades de Filosofia Ciências e Letras poderiam ser escolhidos com vistas à formação para a profissão docente. Desta forma, no Brasil, a criação do ensino superior sempre esteve permeada por um ideário baseado pela relação entre formação-mercado de trabalho, no qual prevalecia a noção de que a formação deveria corresponder sempre a uma especialidade técnica, a uma profissão. Portanto, seria incoerente a ideia de criar cursos envolvidos unicamente com a pesquisa, sem uma profissão correspondente (SUCUPIRA, 1969). Assim, mesmo que o curso não correspondesse a uma formação profissional tradicional da época, ele poderia ser atrelado à formação de professor secundário, ainda pouco estimada. Desta forma, começava a se constituir o magistério como profissão no cenário universitário nacional.

Neste contexto, em 1934, foram iniciadas duas experiências com a formação de professores secundários, na Universidade de São Paulo e na Universidade do Distrito Federal. Embora as experiências na Universidade do Distrito Federal tenham se dado sensivelmente de maneira mais flexível, na Universidade de São Paulo, a dualidade entre a formação para a pesquisa e/ou formação para docência se caracterizou pela sistematização do próprio processo de formação, no qual o aluno de graduação deveria cursar três anos de bacharelado e mais um ano de disciplinas pedagógicas e prática de ensino para a formação profissional docente. As tensões geradas na discussão sobre o papel da universidade ganharam representatividade inclusive na sistematização de alguns cursos de formação (não profissionais), nos quais três anos eram destinados à formação bacharelesca e um ano destinado à formação pedagógica e prática de ensino, caso fosse do interesse do discente obter o licenciamento para o magistério. A partir dessa conformação do curso de licenciatura, se torna possível dimensionar o menor prestígio dado à formação docente, que embora seja uma profissão, não possui o mesmo peso daquelas tradicionais consideradas na época (AYRES, 2005).

Foi neste cenário de criação dos cursos ditos não profissionais, que em 1934, foi inaugurado o primeiro curso de História Natural pela Faculdade de Filosofia, Ciências e Letras da Universidade de São Paulo (CASSAB, 2012). Como o Estatuto das universidades brasileiras não trouxe regulações sobre conteúdos a serem desenvolvidos por cursos oferecidos pelas Faculdades de Filosofia, Ciência e Letras, ficou a cargo de cada instituição elaborar seu programa de ensino para cada determinado curso. 
Entretanto, anos mais tarde, as universidades pioneiras na formação de professores ou foram totalmente extintas, como a Universidade do Distrito Federal; ou passaram por reformas a partir da promulgação da lei 452 de 5 de julho de 1937 que instituiu a Universidade do Distrito Federal, no Rio de Janeiro, e a definiu como instituição modelo com a função de fixação do padrão de ensino superior no país (FAVERO, 2007). Com a padronização do ensino superior, tanto a Faculdade de Filosofia, Ciência e Letras da Universidade de São Paulo, quanto a Faculdade Nacional de Filosofia da Universidade do Brasil, "passam a conter - além das seções científicas e humanísticas - uma seção de educação, responsável pela formação pedagógica e profissional dos professores, a ser cursada ‘em um ano' após se completar o bacharelado de 3 anos” (AYRES, 2005, p. 18).

Com isso, pode-se dizer que a formação de professores secundários no Brasil, ou seja, a formação de professores em nível superior, ou ainda, as licenciaturas, surgiram juntamente com a formação de bacharéis da mesma área, que por sua vez, coincide também com a organização da própria universidade brasileira. Nestes primeiros anos em que se estabelece a estrutura universitária não conseguimos localizar em algum documento regulador a intenção de se realizar abordagens sobre saúde na formação de professores. O único indício sobre a possibilidade da abordagem sobre saúde em documentos reguladores é observável no Decreto n 19.890 de 18 de abril de 1931 que dispõe sobre a organização do ensino secundário, mais precisamente, no tocante às disciplinas que deveriam compor o curso complementar, obrigatório para os candidatos à matrícula em determinadas instituições de ensino superior.

comprehenderá as seguintes materias: Allemão ou Inglez, Latim, Litteratura, Geographia, Geophysyca e Cosmographia, Historia da Civilização, Mathetatica, Physuca, Chimica, historia natural, Biologia geral, Hygiene, Phychologia e Logica, Sociologia, Noções de Economia e Estatistica, Historia da Philosophia e Desenho (BRASIL, 1931).

A disciplina de "Hygiene" figura dentre as elencadas para o curso complementar. $\mathrm{Na}$ seção anterior, identificamos que historicamente as disciplinas sobre higiene no contexto escolar esteve responsável pela abordagem, mesmo que reduzida, da saúde neste espaço. Por isso, interpretamos que a disciplina Higiene estando elencada como obrigatória no curso complementar que prepara o aluno secundarista para o ensino superior na Faculdade de Filosofia, Ciência e Letras, seria cursada por todos os egressos da formação de professores na universidade. Porém, o decreto sinaliza no oitavo artigo que "o regulamento da Faculdade de Educação, Ciencias e Lettras discriminará quais as materias do curso complementar que serão exigidas para a matricula em seus cursos" (BRASIL, 1931). Logo, o contato com abordagens sobre saúde através da disciplina "Hygiene" no curso complementar para ingresso na formação de professores de nível superior, era facultada segundo as regras da instituição formadora. 
É importante frisarmos que a estrutura universitária proposta pela Reforma Francisco Campos não se consolidou na prática, já que as Faculdades de Filosofia, Ciências e Letras constituíram-se em uma relação estanque com os demais cursos de nível superior, o que comprometeu o propósito de integralidade e organicidade compreendido como fundamentais à estrutura universitária (CACETEII, 2010). Porém, a partir da década de 1930 foi possível observar uma expansão significativa dos cursos oferecidos pelas Faculdades de Filosofia, Ciências e Letras.

A organização e expansão do ensino secundário passaram a gerar um campo de atuação para os egressos das licenciaturas (SAMPAIO, 2000; CACETEII, 2010); com isso, o número de cursos de formação de professores em nível superior aumentou significativamente, de forma que as instituições da iniciativa privada passaram a ganhar destaque na oferta desses cursos. Os cursos das Faculdades de Filosofia, Ciências e Letras são, no geral, cursos de baixo custo de criação e manutenção, o que justifica o despontar dos cursos particulares na esfera do ensino superior (SAMPAIO, 2000). Esse processo de dupla expansão tanto do ensino secundário, quanto da formação de professores em nível superior acabou por se estender pelas décadas seguintes.

A década de 1960 é marcada pelo início do regime militar, o que significou alterações no funcionamento do ensino superior. No entanto, antes mesmo que o regime se instaurasse, algumas modificações, sobretudo as que se referiam às licenciaturas, foram previamente anunciadas pela $\operatorname{LDB} \mathrm{n}^{\circ}$ 4.024, promulgada em 20 de dezembro de 1961 que desconsiderou a obrigatoriedade dos conjuntos universitários brasileiros possuírem Faculdades de Filosofia, Ciências e Letras, implicando na redução do prestígio para estas faculdades ${ }^{1}$.

Após descrevermos as primeiras décadas do surgimento sistematizado do ensino superior brasileiro, nos dedicamos a diante à regulação específica dos cursos de História Natural, enquanto assim for denominado, e do curso de Ciências Biológicas com ênfase nas licenciaturas desses respectivos cursos. Para tanto, nos orientamos pelos estudos de Haddad (2006) que sequencia historicamente a legislação que tem regulamentado a criação e funcionamento dos cursos de Bacharelado e Licenciatura na área da Biologia, como se observa a seguir:

Parecer CFE 325/62 e Resolução s/nº de 1962: estabeleceram o currículo mínimo de História Natural.

Parecer CESu no 5/63: aprovou o desdobramento do curso de História Natural em curso de Ciências Biológicas e curso de Geologia.

Parecer CESu 30/64: estabeleceu o currículo mínimo de Ciências Biológicas.

Portaria MEC no 510/64: fixou o currículo mínimo para licenciatura e bacharelado de Ciências Biológicas.

\footnotetext{
${ }^{1}$ Para melhor compreensão das alterações dirigidas pela LDB/61 ler (CACETEII, 2010) a partir da página 1067.
} 
Parecer 81/65: estabeleceu a duração e o currículo mínimo para licenciatura em Ciências $1^{\circ}$ grau.

Parecer 571/66: estabeleceu o currículo mínimo para Ciências Biológicas (bacharelado modalidade médica).

Portaria CFE $n^{\circ}$ 25/67: retificou a Portaria MEC $n^{\circ}$ 510/64, estabelecendo o currículo mínimo para o curso de Bacharelado em Ciências Biológicas, modalidade médica.

Resolução CFE de 4 de fevereiro de 1969: estabeleceu o currículo mínimo e duração do curso de Ciências Biológicas com tronco curricular comum para licenciatura e bacharelado, modalidade médica; revogou os currículos mínimos de História Natural e Ciências Biológicas.

Parecer $n^{\circ}$ 107/70 (Resolução de 4 de fevereiro de 1970): organizou o currículo mínimo de Ciências Biológicas (Licenciatura e Bacharelado).

Parecer $n^{\circ}$ 1.687/74 e Resolução CFE 30/74: criou cursos de Ciências, habilitação Biologia - Ciências de $1^{\circ}$ grau (Curta) e Biologia $2^{\circ}$ grau (Plena).

Resolução CFE 37/75: determinou a obrigatoriedade dos cursos de Licenciatura curta em Ciências.

Resolução CFE 5/78: suspendeu a obrigatoriedade dos cursos de Licenciatura curta em Ciências.

Lei no 9.394/1996: estabelece a Lei de Diretrizes e Bases da Educação Nacional.

Resolução CNE no 3/1997: tratou da formação do professor leigo.

Parecer CNE/CP n 9/2001: estabeleceu as Diretrizes Curriculares Nacionais para a Formação de Professores da Educação Básica, em nível superior, curso de licenciatura, de graduação plena.

Parecer CNE/CP n ${ }^{\circ}$ 21/2001: estabeleceu a duração e carga horária dos cursos de Formação de Professores da Educação Básica, em nível superior, curso de licenciatura, de graduação plena.

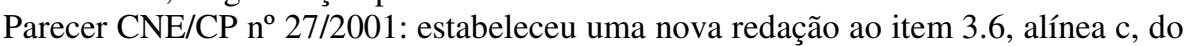
Parecer CNE/CP 9/2001, que dispõe sobre as Diretrizes Curriculares Nacionais para a Formação de Professores da Educação Básica, em nível superior, curso de licenciatura, de graduação plena. Parecer CNE/CP no 28/2001: estabeleceu uma nova redação ao Parecer CNE/ CP 21/2001, que estabelece a duração e a carga horária dos cursos de Formação de Professores da Educação Básica, em nível superior, curso de licenciatura, de graduação plena.

Parecer CNE/CES n ${ }^{\circ}$ 1.301/2001: estabeleceu as Diretrizes Curriculares Nacionais para os cursos de Ciências Biológicas.

Resolução CNE/CP n ${ }^{\circ}$ 1/2002: instituiu as Diretrizes Curriculares Nacionais para a Formação de Professores da Educação Básica, em nível superior, curso de licenciatura, de graduação plena.

Resolução CNE/CP n ${ }^{\circ}$ 2/2002: instituiu a duração e a carga horária dos cursos de licenciatura, de graduação plena, de formação de professores da Educação Básica em nível superior. Resolução CNE/CES no 7/2002: estabeleceu as Diretrizes Curriculares para os cursos de Ciências Biológicas (p. 56-55).

Tomamos para leitura alguns desses documentos históricos na busca por orientações à abordagem da saúde nas licenciaturas da área de Ciências Biológicas. Contudo, nos dedicamos apenas àqueles que tratam da fixação de currículo mínimo ou da orientação de conteúdos para a Licenciatura em Ciências Biológicas (LCB) plena ou equivalente, que formam professores para atuarem no ensino secundário e médio, atualmente denominado ensino fundamental II e ensino médio.

No ano de 1962 o Conselho Federal de Educação (CFE) foi responsabilizado pelo dever de estabelecer o currículo mínimo dos cursos de ensino superior, em atendimento às orientações dirigidas pela LDB de 1961. Com essa função, o CFE fixou o primeiro currículo de História Natural que se observa a seguir: 
1. Biologia (Citologia; Histologia; Embriologia e Genética)

2. Botânica (Morfologia; Fisiologia e Sistemática)

3. Zoologia (Morfologia, Fisiologia; Sistemática)

4. Mineralogia e Petrologia

5. Geologia e Paleontologia

6. Matérias Pedagógicas

6.1- Psicologia da Educação; Adolescência; Aprendizagem

6.2- Elementos de Administração Escolar

6.3- Didática

6.4- Prática de Ensino, sob a forma de estágio supervisionado (BRASIL,1962, p. 94-99).

Essa relação de disciplinas compreende o denominado currículo mínimo que, segundo o conselheiro Newton Sucupira, consiste no "núcleo mínimo necessário de matérias, abaixo do qual ficaria comprometida uma adequada formação profissional” (BRASIL, 1962, p. 147). Caberia a cada instituição de nível superior cumprir com o mínimo fixado e complementar com quantas matérias, ou disciplinas ou atividades fossem necessárias para a formação do profissional licenciado para a docência. Sendo assim, observamos que a abordagem sobre saúde não figurava no currículo mínimo orientado e, desta forma, a abordagem da saúde na formação desses profissionais era facultada à decisão de cada instituição.

Dois anos depois, um novo currículo mínimo foi fixado para a formação em nível superior na área das Ciências Biológicas. Esse período é marcado pelo desdobramento do curso de História Natural em curso de Ciências Biológicas e curso de Geologia aprovado pelo Parecer CESu $n^{\circ}$ 5/63. Portanto, tratamos aqui da fixação do currículo mínimo do recémcriado curso de Ciências Biológicas, elencando as seguintes disciplinas que se seguem:

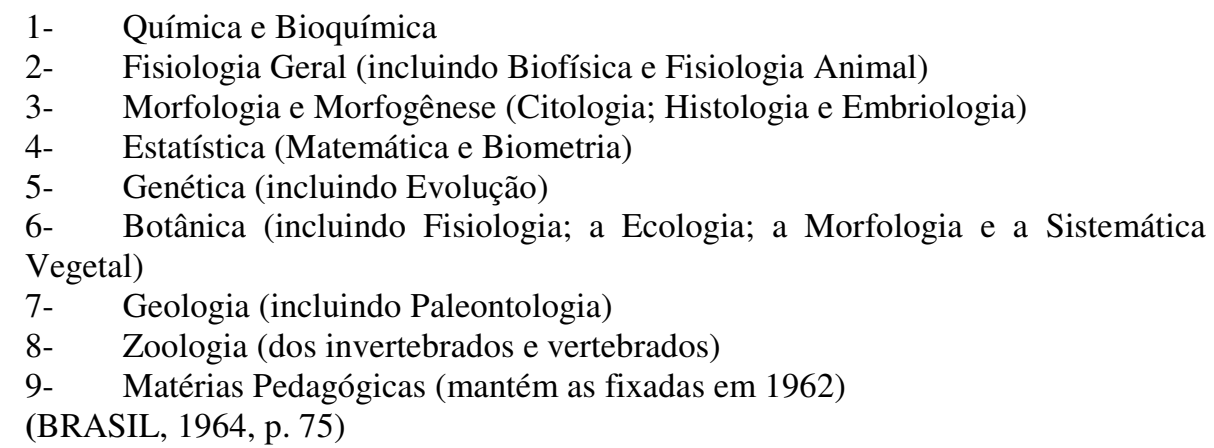

Podemos observar que o currículo mínimo aumentou significativamente o quantitativo de disciplinas, embora as disciplinas classificadas como pedagógicas destinadas à formação de professores não tenham sofrido alteração alguma, sendo as mesmas fixadas pelo currículo mínimo divulgado em 1962. Apesar de ter ocorrido uma expansão das disciplinas a serem ministrados nas recém-criadas LCB, quando comparada com o currículo da Licenciatura em História Natural, não foi considerada uma orientação direta ao trabalho com a saúde na formação destes professores. Acreditamos que a expansão no quantitativo de disciplinas tenha aumentado as possibilidades de que as abordagens sobre saúde acontecessem em uma disciplina ou outra, porém segundo o interesse ou aptidão do professore responsável, sem 
estarem garantidas pelas orientações do currículo mínimo ou então, como disciplina complementar acrescida segundo ao interesse ou perfil de determinada instituição e/ou professor.

No ano de 1970, o CEF estabeleceu novamente um currículo mínimo para o curso de Ciências Biológicas. A fixação do novo currículo significou a redução da ênfase dada às geociências como acontecia nas Licenciaturas em História Natural. Sendo assim, disciplinas ligadas às Ciências Físicas, Matemáticas e Química passaram a ser consideradas na formação dos professores de Ciência Biológicas, consonante com as exigências da formação escolar. Desta forma, foi estabelecido um tronco comum partilhado entre a licenciatura e o bacharelado e um tronco de disciplinas específicas da formação de professores como se observa a seguir:

1- Tronco comum à licenciatura e bacharelado

Biologia Geral (incluindo Citologia, Genética, Embriologia, Evolução e Ecologia)

Matemática Aplicada

Física e Biofísica

Química e Bioquímica

Elementos de Fisiologia, de Anatomia e Fisiologia Humana

2- $\quad$ Tronco específico da licenciatura

Zoologia (incluindo Morfologia, Morfogênese, Fisiologia, Sistemática e Ecologia dos animais Vertebrados e Invertebrados)

Botânica (incluindo Morfologia, Fisiologia, Sistemática e Ecologia das Plantas e Botânica Econômica)

Geologia (incluindo Paleontologia)

Matérias Pedagógicas (BRASIL, 1970, p. 178)

As matérias pedagógicas que compõem o tronco específico da licenciatura foram fixadas pelo parecer 252/69 o qual não tivemos acesso. O currículo fixado para as Licenciaturas em Ciências Biológicas deu destaque às disciplinas próprias da área de Ciências Biológicas, as quais compreendemos como heranças do curso de História Natural, como as disciplinas de Geologia e Paleontologia, mas passam a prevalecer as disciplinas das Ciências Biológicas. A fixação do seguinte currículo seguiu o movimento de busca pela identidade do curso de Ciências Biológicas, porém ao que se refere à saúde, não houve designação direta para seu desenvolvimento na formação de professores de Ciências e Biologia. Todavia, acreditamos que à medida que o currículo mínimo fixado se torna cada vez mais próprio das Ciências Biológicas e que as exigências escolares passam a ser consideradas em sua estruturação, há maior possibilidade de que a abordagem pedagógica da saúde ocorra transversalmente entre as disciplinas curriculares, no entanto, não podemos chegar a essa conclusão baseados somente pelo currículo mínimo.

Em 1974, o Parecer $n^{\circ} 1.687 / 74$ e a Resolução CFE 30/74 criaram os cursos de Licenciatura curta em Ciências e o Curso de Licenciatura plena em quatro disciplinas possíveis, dentre elas a Biologia. Como nos interessamos pelos cursos de Licenciatura plena, 
trataremos aqui da Licenciatura plena em Biologia e seu respectivo currículo mínimo fixado, como se reproduzido a seguir:

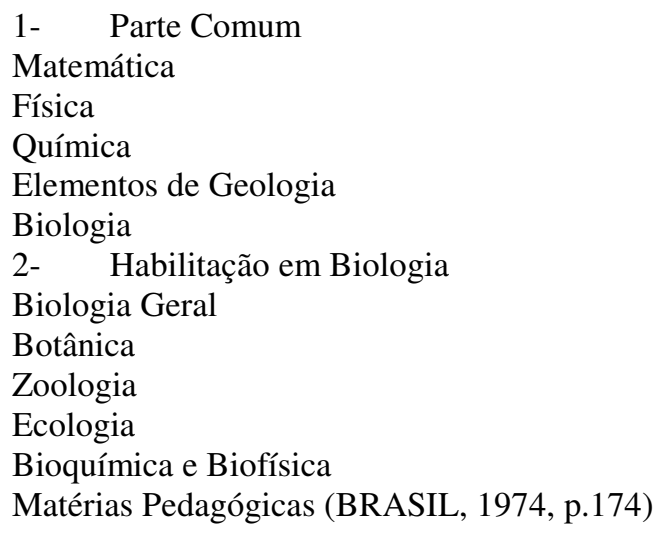

Embora o currículo mínimo representado acima trate da formação em Licenciatura plena em Biologia, a parte denominada "Parte comum" destacada da "Habilitação em Biologia", sob a regulação deste parecer e resolução, configurava a formação em Licenciatura curta em Ciências, na qual o professor formado poderia lecionar no primeiro ciclo escolar a disciplina de Ciências. Após ter completado a parte comum, o licenciando poderia cursar a complementação para a obtenção do diploma de Licenciatura plena nas seguintes áreas: Matemática, Química, Física e Biologia. Como se pode notar, não há apontamento algum para o desenvolvimento da saúde no currículo mínimo fixado, com a possibilidade de obtenção de uma habilitação em Ciências Biológicas ao cursar a primeira etapa do curso; a parte comum ficou estruturada de maneira diversificada, posto que a disciplina ciências do primeiro ciclo escolar engloba várias áreas disciplinares. Sendo assim, acreditamos que tal diversificação na "Parte Comum" do currículo comprometeu a formação específica da Licenciatura Plena em Biologia.

As LDB de 1971 e 1996 não especificam qualquer orientação sobre a abordagem da saúde no ensino superior. Três anos após a vigência da LDB/71, o Parecer 2.264/1974 regulamentou os Programas de Saúde a serem desenvolvidos nas escolas com o intuito de romper com a abordagem reducionista da saúde herdada do século anterior. Como principal estratégia de inovação, o parecer propõe que a saúde seja abordada interdisciplinarmente, de modo a contar com a contribuição das diferentes áreas disciplinares que compõem o currículo da educação básica. Entretanto, na prática, os Programas de Saúde serviram apenas para a criação de mais uma disciplina escolar e para produção de materiais didáticos, pois os conteúdos do tema saúde trabalhados nas escolas ainda eram fortemente marcados pelas intenções sanitaristas e higienistas (MOHR, 2002).

Os documentos reguladores mais recentes possuem como consenso a intenção de construir uma sintonia entre a regulação da formação de professores em ensino superior e as 
orientações prescritas pela LDB, pelos PCN e pelos Referenciais Curriculares das Licenciaturas (BRASIL, 2001a, 2001b, 2002), de modo que as orientações curriculares para a formação de professores estejam alinhadas com as orientações curriculares da educação básica. Logo, embora os documentos que regulam as licenciaturas como um todo não tratem especificamente da questão da saúde, eles sinalizam a intenção de estabelecer conformidades com as orientações curriculares para educação básica nas orientações para formação de professores, o que indiretamente garantiria a saúde nas licenciaturas.

No caso do documento que regula especificamente as LCB é atribuído ao perfil do aluno formado pelo respectivo curso, dentre outras características, a consciência da necessidade de atuar com qualidade e responsabilidade em prol das políticas de saúde (BRASIL, 2001b), além disso, orienta o trabalho com a saúde na área de ecologia ao sinalizar como um dos conteúdos básicos a relação entre saúde, educação e ambiente (idem).

Ao que se refere à ES, a entendemos como a combinação de qualquer experiência de aprendizagem planejada com a finalidade de facilitar ações que favoreçam à saúde e a Promoção da Saúde, sendo a combinação de apoios educacionais (por meio da ES) e ambientais (circunstâncias sociais, políticas, econômicas, organizacionais, reguladoras, relacionadas ao comportamento humano, políticas de saúde) que possuam o objetivo de alcançar condições de vida favoráveis à saúde (CANDEIAS, 1997). Compreendemos que a ES é um dos apoios pelo qual se torna possível a Promoção da Saúde, no entanto, este apoio se constitui como "um campo de trabalho e exercício pedagógico" (MOHR, 2002, p. 44) que se legitima pela reflexão, pesquisa e intervenção do profissional da educação na mobilização de determinados conceitos próprios da área da saúde, porém envolvendo-os por intenções pedagógicas ao invés de simplesmente importá-los e repeti-los nos espaços educativos.

Assim, entendemos que o documento regulador da saúde na Formação de Professores de Ciências Biológicas encontra-se alinhado com os direcionamentos dos estudos produzidos no campo da ES. Direcionamentos estes que tornam amplos os sentidos do conceito de saúde, envolvendo-o de compromisso político na formação dos futuros docentes bem como a superação das fronteiras fisiologicistas e biologizante, inscrevendo o conceito na tríade da saúde, educação e ambiente. Entretanto, ressaltamos que nossas análises foram baseadas em documentos reguladores, é fundamental a produção de estudos que se dediquem à materialização da abordagem da saúde na formação dos respectivos professores. Perguntas como (A saúde tem sido contemplada na formação de professores? Como tem sido contemplada? Quais os sujeitos responsáveis pela ES na Formação de Professores?) desafiam a produção de estudos no campo da ES. 


\section{Considerações finais}

A análise histórica empreendida neste estudo nos dá indícios sobre o distanciamento entre a produção de documentos reguladores da educação escolar daqueles documentos direcionados ao ensino superior, neste caso, à Formação de Professores. Consideramos que embora a saúde tenha sido posta como uma demanda a ser encarada no âmbito da educação escolar, a mesma questão não esteve inserida nos cursos de formação dos futuros docentes com devida atenção e aprofundamento. Como vimos na seção de introdução, ao longo da história, o conceito de saúde esteve minimamente compreendido por uma perspectiva fisiológica, biológica e também higiênica que se manteve estável por muito tempo e exerce influências sobre a compreensão de saúde atual. Em contrapartida, o professor desponta como sujeito chave na disseminação de um ideário sobre saúde, todavia, a análise dos documentos destinados à Formação de Professores, de História Natural e Ciências Biológicas como se delimita o presente estudo, nos revela que a questão da saúde foi considerada tardiamente quando comparado à educação escolar.

Nesse sentido, acreditamos que o não diálogo ou até mesmo a distância entre as regulações, no que tange a saúde, da educação escolar e a Formação de Professores contribuiu para a formação de profissionais não aptos para o enfrentamento da questão da saúde no âmbito escolar. Denominamos enfrentamento no sentido de os professores com formação acadêmica poderem contrapor o sentido reduzido dado à saúde. Ao contrário disso, o que os estudos indicam é a atuação de professores que abordam um conceito de saúde restrito ao senso comum (COLLARES; MOYSÉS, 1985; MOHR, 2002) e/ou restrito à perspectiva biomédica "não havendo o desejável aprofundamento das questões de saúde quando curricularmente abordadas" (BAGNATO, 1990, p. 56).

Consideramos que o ensino primário delimitou a iniciativa de introdução da saúde no âmbito educacional, principalmente pelo fato de que no final do século XIX e início do século XX este era o nível de educação mais acessível à população. A formação de professores primários também sediou a inserção de conteúdos sobre saúde em seus programas de ensino através de uma disciplina responsável por tratar de questões de higiene. Com o avançar da educação brasileira, o ensino secundário ganhou expressão no país e aumentou exponencialmente constituindo-se como um novo campo de trabalho para os professores secundários, formados no recém estruturado ensino superior brasileiro. A saúde, uma vez inserida no ambiente escolar, manteve-se presente até a atualidade, inicialmente através da disciplina higiene, através dos Programas de Saúde e com o passar dos anos esteve representada associada a outros temas como o ambiente, a sexualidade ou então esteve 
brevemente abordada no escopo das disciplinas que compõem o currículo da educação básica, dentre elas, Ciências e a Biologia.

Notamos que embora a abordagem da saúde tenha se mantido na educação básica, as orientações para os cursos de Formação de Professores em ensino superior em História Natural e, posteriormente, Ciências Biológicas não contemplavam a questão da saúde. Apenas nos documentos mais recentes de orientações das LCB é possível identificar uma relação consensual para a abordagem da saúde na Formação dos Professores de Ciências Biológicas assim como é indicada na educação básica (BRASIL, 2001b).

Encontrar orientações comuns na regulação da educação básica e do ensino superior no que tange a contemplação da abordagem da saúde é algo inédito na história de publicação destes documentos. A maior parte das produções, no campo da ES, vêm sinalizando que mesmo sob à luz destes documentos mais recentes, as licenciaturas não têm contemplado a questão da saúde na formação de professores (LEONELLO; L’ABBATE, 2006; ZANCUL; GOMES; 2011; GUSTAVO, 2015). Essas ausências contribuem para que "a relação entre o que o estudante aprende na licenciatura e o currículo que ensinará no segundo segmento do ensino fundamental e no ensino médio continuem abissal" (PEREIRA, 2000, p. 221). Ainda que os documentos reguladores aos quais nos referimos aqui datem de quatorze a quinze anos atrás, compreendemos que o processo de modificação e/ou reformas das estruturas curriculares no ensino superior são graduais e lentas, ao passo que, mesmo ainda incipiente, identificamos iniciativas de algumas LCB na abordagem da saúde (GUSTAVO, 2015).

A análise histórica nos fornece elementos que nos ajudam a entender as heranças ligadas a ES atualmente proposta para a educação básica e a Formação de Professores de Ciências e Biologia. A história que envolve o conceito de saúde inscreve os campos de ES e Ensino de Ciências como campos contíguos que precisam se debruçar conjuntamente sobre o ensinar/educar/promover a saúde na área disciplinar de Ciências. O desafio é ainda maior, quando pomos em questão a Formação de Professores em Ciências Biológicas, a análise histórica nos permite apreender o quanto a questão da saúde foi negligenciada nesses cursos, constituindo uma herança negativa. O parágrafo anterior aponta que mesmo sob regulações alinhadas com as definições mais atuais da saúde e com as regulações da educação básica, ainda são encontradas Licenciaturas em Ciências Biológicas que não consideram a questão da saúde. Sendo assim, o desafio que se configura na atualidade é o de construir propostas de abordagem da saúde para a Formação de Professores, bem como o aprofundamento das iniciativas em que elas acontecem. 


\section{Referências}

GUSTAVO, L.S. A Educação em Saúde na Licenciatura em Ciências Biológicas: abordagens e conhecimentos. 107f. Dissertação de Mestrado. Programa de Pós-Graduação em Ensino de Ciências, Ambiente e Sociedade, FFP-UERJ. Rio de Janeiro-RJ. 2015.

AYRES, A. C. M. As tensões entre a licenciatura e o bacharelado: a formação dos professores de Biologia como territórios contestados. In: MARANDINO, M.; SELLES, S. E.;

FERREIRA, M. S.; AMORIM, A. C. R. (Org.). Ensino de Biologia: conhecimentos e valores em disputa. Niterói-RJ: EdUFF, 2005. p. 182-197

BAGNATO, M.H.S. O ensino da saúde nas escolas de $1^{\circ}$ grau. Pró-Posições, p. 53-59, 1990.

BAPTISTA, T. W. F. História das políticas de saúde no Brasil: a trajetória do direito à saúde. In: MATTA, G. C. (Org.).Políticas de Saúde. Organização e operacionalização do Sistema Único de Saúde. Rio de Janeiro: EPSJV/Fiocruz, 2007. p. 29-60

BRASIL. Decreto $\mathrm{n}^{\circ} 10.890$ de 18 de abril de 1931. Organização do ensino secundário. Disponível em: <http://www2.camara.leg.br/legin/fed/decret/1930-1939/decreto-19890-18abril-1931-504631-publicacaooriginal-141245-pe.html>.

BRASIL. Parecer CFE 315/62, de 14 de novembro de 1962. Currículo Mínimo de História Natural. Revista Documenta, Brasília, no 10, dez., 1962.

BRASIL. Portaria MEC nº 510/64, de 26 de julho de 1964. Currículo Mínimo do curso de Ciências Biológicas. Revista Documenta, Brasília, nº 29, dez., 1964.

BRASIL. Parecer 107/70, de 4 de Fevereiro de 1970. Currículo Mínimo dos Cursos de Ciências Biológicas. Revista Documenta, Brasília, nº 111, fev., 1970.

BRASIL. Lei n ${ }^{\circ} 5.692$ de 11 de agosto de 1971. Fixa diretrizes e bases para o ensino de $1^{\circ} \mathrm{e}$ $2^{\circ}$ graus, e dá outras providências. Revista Documenta, Brasília, nº129, p. 400-416, 1971.

BRASIL. Parecer no 1.687/74, de 07 de junho de 1974. Curso de Licenciatura em Ciências, mínimo de conteúdo e duração. Revista Documenta, nº 163, 1974.

BRASIL. Parecer 2.264/74. Ensino ( $1^{\circ}$ e $2^{\circ}$ graus) Educação da Saúde. Programas de Saúde. Revista Documenta, Brasília, nº 165, p. 63-81, 1974.

BRASIL. Ministério da Saúde. Relatório da VIII Conferência Nacional de Saúde. Brasília, 1986.

BRASIL. Lei Federal nº. 8.142/1990 de 28 de dezembro de 1990. Dispõe sobre a participação da comunidade na gestão do Sistema único de Saúde e sobre as transferências intergovernamentais e recursos financeiros na área da saúde e dá outras providências. Diário Oficial da União, 1990.

BRASIL. Lei 9.394/1996. Ministério da Educação. Lei de Diretrizes e Bases da Educação Nacional. 1996.

BRASIL. Secretaria de Educação Fundamental. Parâmetros Curriculares Nacionais: terceiro e quarto ciclos do ensino fundamental: introdução aos parâmetros curriculares nacionais, Brasília: MEC, 1997. 
BRASIL. Secretaria de Educação Fundamental. Parâmetros Curriculares Nacionais: ciências naturais. Brasília: MEC /SEF, 1998.

BRASIL. Parecer CNE/CP 9/2001. Diretrizes Curriculares Nacionais para a Formação de Professores da Educação Básica, em nível superior, curso de licenciatura, de graduação plena, Brasília, 2001a.

BRASIL. Parecer CNE/CES 1.301/2001. Diretrizes Curriculares Nacionais para os Cursos de Ciências Biológicas, 2001b.

BRASIL. Resolução CNE/CES 7/2002. Estabelece Diretrizes Curriculares para os cursos de Ciências Biológicas, 2002.

BRASIL. Portaria Normativa no 40, de 12 de dezembro de 2007. Brasília: MEC, 2007. Disponível em: <http://meclegis.mec.gov.br/documento/view/id/17>. Disponível em: 21 jul. 2014.

BRASIL. Ministério da Educação. Programa Saúde nas Escolas. Brasília, 2010. Disponível em: <http://portal.mec.gov.br/index.php?option=com_content\&view

$=$ article \&id=14578:programa-saude-nas-escolas\&catid=194: secad-educacao-continuada $>$. Acesso em: 24 fev. 2015.

BUSS, P. O Conceito de Promoção da Saúde e os Determinantes sociais. Agência Fiocruz de Notícias, [S.1.], p. 1-3, 2010.

CACETEII, N. H. Breve história do ensino superior brasileiro e da formação de professores para a escola secundária. Revista Educ. Pesqui., [S.1.], v. 40, n. 4, p. 1061-1076, 2014.

CANDEIAS, N. M. F. Conceitos de educação e de promoção em saúde: mudanças individuais e mudanças organizacionais. Revista de Saúde Pública, [S.1.], v. 31, n. 2, p. 209-213, 1997.

CARDOSO DE MELO, J. A. Educação e as Práticas de Saúde. In: ESCOLA POLITÉCNICA DE SAÚDE JOAQUIM VENÂNCIO (Org.). Trabalho, Educação e Saúde: reflexões críticas de Joaquim Alberto Cardoso de Melo. Rio de Janeiro: EPSJV, 2007.

CASSAB, M. A construção sócio-histórica da biologia escolar no Colégio Pedro II (1961-1981): renovação e tradição. In: GALIETA-NASCIMENTO, T. (Org.). Ensino de Ciências em programas de pós-graduação no Brasil: tendências de pesquisa. Curitiba-PR, CRV, 2012. p.1-214.

COLlARES, C. A. L.; MOYSÉS, M. A. A. Educação ou saúde? Educação X saúde? Educação e saúde! Caderno CEDES, Campinas, n. 15, p. 7-16, 1985.

CUNHA, L. A. A Universidade Temporã: O Ensino Superior da Colônia à Era Vargas. Rio de Janeiro, Civilização Brasileira, 1980.

EBERHARDT, T.D.; REIS, L.F. Programa Saúde na Escola - PSE: Estruturado de acordo com os princípios dos SUS? ANAIS DO $5^{\circ}$ SEMINÁRIO NACIONAL ESTADO E POLÍTICAS SOCIAIS, ISSN 2175-425x. Unioeste, Cascavel-PR, 2011. 
FAVERO, M. L. A. A Universidade Federal do Rio de Janeiro: origens e construção (1920 a 1965). In: OLIVEIRA, A. J. B. (Org.). A Universidade e os múltiplos olhares de si mesma. 1ed. Rio de Janeiro: UFRJ/FCC/SIBI, 2007. p.13-42,

FOCESI, E. Educação em Saúde na escola: O papel do professor. Revista Brasileira Saúde do Escolar, [S.1.], v. 1, n. 2, p. 4-8, 1990.

FREITAS, E. O.; MARTINS, I. Concepções de saúde no livro didático de ciências. Revista Ensaio Pesquisa em Educação em Ciências, [S.1.], v. 10, n. 2, p. 222-248, 2009.

GOUVÊA, L. A. V. N. Educação para Saúde na Legislação Educacional no Brasil. SEMINÁRIO NACIONAL ESTADO E POLÍTICAS SOCIAIS NO BRASIL. Unioeste, Cascavel-PR, 2007.

HADDAD, A. E. A trajetória dos cursos de graduação na área da saúde: 1991-2004. Brasília, Instituto Nacional de Estudos e Pesquisas Educacionais Anísio Teixeira, 2006.

LEONELLO, V.M.; L'ABBATE, S. Educação em Saúde na escola: uma abordagem do currículo e da percepção de alunos de graduação em Pedagogia. Revista Interface, v. 10, n. 19, p.149-166, 2006.

MOHR, A. A natureza da Educação em Saúde no ensino fundamental e os professores de ciências. 2002. 406 f. Tese Doutorado (Educação). Centro de Ciências da Educação, Universidade Federal de Santa Catarina-SC, 2002.

SAMPAIO, H. Ensino superior no Brasil: o setor privado. São Paulo: Hucitec, FAPESP, 2000.

SANTOS, M.C.F. A Higiene, a História Natural e a Biologia na educação escolar: considerações sobre conhecimentos nos programas de ensino da Escola Normal do Distrito Federal (1904-1946). In: XVI ENCONTRO REGIONAL DE HISTÓRIA DA ANPUH. Rio de Janeiro. Anais, 2014.

SILVA, R.M.L. O Movimento de Renovação da Educação e o Cinema Educativo. In: SIMPOSIO NACIONAL DE HISTÓRIA DA ASSOCIAÇÃO NACIONAL DE HISTÓRIA-ANPUH. Anais, 2007.

SUCUPIRA, N. Da faculdade de filosofia à faculdade de educação. Revista Brasileira de Estudos Pedagógicos, RJ, v. 51, n. 114, p. 261-276, abr.-jun. 1969.

PEREIRA, D. J. E. Formação de professores-pesquisa, representações e poder. Belo Horizonte-MG, Autêntica, 2000.

VENTURI, T.; MOHR, A. Análise da Educação em Saúde em publicações da área da Educação em Ciências. In: ENCONTRO DE PESQUISA EM EDUCAÇÃO E I CONGRESSO IBEROAMERICANO DE INVESTIGAÇÃO E ENSINO DE CIÊNCIAS. Atas, 2011.

ZANCUL, M.S.; GOMES, P.H.M. A formação de licenciandos em Ciências Biológicas par trabalhar temas de Educação em Saúde na escola. Revista Ensino, Saúde e Ambiente, v.4, n.1, p.49-61, abr., 2011. 


\section{SOBRE OS AUTORES}

LUAN DA SILVA GUSTAVO. Graduado em Licenciatura em Ciências Biológicas pela Universidade Federal do Rio de Janeiro (UFRJ); Mestre em Ensino de Biologia pelo Programa de Pós-Graduação em Ensino de Ciências, Ambiente e Sociedade (PPGEAS) da Faculdade de Formação de Professores da Universidade do Estado do Rio de Janeiro (FFPUERJ). Atualmente é professor de Ciências da rede municipal de educação da cidade do Rio de Janeiro e na Educação de Jovens e Adultos da Escola Politécnica de Saúde Joaquim Venâncio - Fiocruz.

TATIANA GALIETA. Graduada em Ciências Biológicas Licenciatura e Bacharelado em Genética pela Universidade Federal do Rio de Janeiro (UFRJ), Mestre em Educação em Ciências e Saúde pela UFRJ e Doutora em Educação Científica e Tecnológica pela Universidade Federal de Santa Catarina. Professora Adjunta da Universidade do Estado do Rio de Janeiro (UERJ). Atualmente é Coordenadora Adjunta e Docente permanente do Programa de Pós-Graduação Ensino de Ciências, Ambiente e Sociedade (PPGEAS), Faculdade de Formação de Professores, UERJ. Coordenadora do Subprojeto Biologia (FFP/UERJ) do PIBID/CAPES.

Recebido: 03 de outubro de 2016.

Revisado: 25 de abril de 2017.

Aceito: 25 de maio de 2017. 